OPEN ACCESS

Edited by:

Haider H. Dar

University of Pittsburgh, United States

Reviewed by:

Vincent Tam,

Temple University, United States

Olga Krysko,

Ghent University, Belgium

*Correspondence:

Zuo-jiong Gong zjgong@163.com

Specialty section:

This article was submitted to Molecular Bacterial Pathogenesis,

a section of the journal

Frontiers in Cellular and Infection

Microbiology

Received: 19 December 2019

Accepted: 14 April 2020

Published: 05 May 2020

Citation:

Shi C-x, Wang Y, Chen Q, Jiao F-z, Pei $M-h$ and Gong Z-j (2020) Extracellular Histone H3 Induces Pyroptosis During Sepsis and May Act Through NOD2 and VSIG4/NLRP3 Pathways.

Front. Cell. Infect. Microbiol. 10:196. doi: 10.3389/fcimb.2020.00196

\section{Extracellular Histone H3 Induces Pyroptosis During Sepsis and May Act Through NOD2 and VSIG4/NLRP3 Pathways}

\author{
Chun-xia Shi, Yao Wang, Qian Chen, Fang-zhou Jiao, Mao-hua Pei and Zuo-jiong Gong* \\ Department of Infectious Diseases, Renmin Hospital of Wuhan University, Wuhan, China
}

Background: Histones could be released from the nucleus when stimulated. Increasing evidence has shown that extracellular histones are associated with a variety of inflammation and diseases. Nucleotide binding oligomerzation domain 2 (NOD2) belongs to the NOD like receptor (NLR) family and is reported to promote apoptosis and aggravate inflammatory response. And V-set and immunoglobulin domain containing 4 (VSIG4), a B7 family-related protein, has been confirmed to mediate transcriptional inhibition of nucleotide-binding oligomerization domain-like receptor protein 3 (NLRP3). However, little is known about the impact of extracellular histones on NOD2 or VSIG4 signal transduction. In this study, we aim to explore the effect and mechanism of extracellular histone $\mathrm{H} 3$ on pyroptosis.

Aim: The purpose of this work was to investigate the mechanism of extracellular histone H3 on pyroptosis in sepsis.

Methods: Lipopolysaccharide (LPS) and histone H3 were used to induce sepsis mice model and damage in ANA-1 macrophages. H3 antibody was applied to antagonize the effect of histone H3. NOD2 inhibitor NOD-IN-1 and VSIG4-siRNA were used to investigate the mechanism of histone $\mathrm{H} 3$ on pyroptosis. Enzyme linked immune sorbent assay (ELISA) was applied to detect the level of extracellular histone H3. Real-time PCR and Western blotting were employed to detect the key mRNA and protein levels. The pathology of tissues was detected.

Results: The level of extracellular histone $\mathrm{H} 3$ was increased after LPS stimulation. The mRNA and protein levels of NLRP3, caspase-1, gasdermin D (GSDMD), interleukin (IL)-1 $\beta$, IL-18 were increased in LPS group, but suppressed by $\mathrm{H} 3$ antibody. And the expression of NOD2, receptor-interacting protein 2 (RIP2) was elevated compared with control group. The expression of VSIG4 was inhibited by LPS and suppression of $\mathrm{H} 3$ promoted the protein level of VSIG4. H3 antibody alleviated pathological damages in tissues. Furthermore, the mRNA and protein levels of NOD2 in $\mathrm{H} 3$ group was higher compared with control group. The mRNA and protein levels of VSIG4 in H3 group was decreased compared with control group, but 


\section{up-regulated by NOD-IN-1. Besides, the mRNA and protein levels of VSIG4 in NOD-IN-1 + VSIG4-siRNA group was elevated compared with VSIG4-siRNA group.}

Conclusions: Extracellular histone $\mathrm{H} 3$ induced by LPS could cause pyroptosis during sepsis via NOD2 and VSIG4/NLRP3 pathway.

Keywords: histone H3, pyroptosis, sepsis, NOD2, VSIG4

\section{INTRODUCTION}

Sepsis is a severe life-threatening systemic inflammatory response syndrome with complex pathogenesis, high mortality, which can cause dysfunction of multiple systems and organs in the body (Rhodes et al., 2017). Immune dysfunction runs through the whole development process of sepsis, and the imbalance between pro-inflammatory mediators and anti-inflammatory mediators plays an important role (Liu and Sun, 2019). Moderate immune response can effectively protect the body, while excessive immune activation or immunosuppression can lead to severe organ dysfunction (Gao et al., 2016). Despite rising medical standards, sepsis still lacks effective treatments. Lipopolysaccharide (LPS) is the main stimulus to induce sepsis, which can activate inflammatory cells through multiple pathways such as toll-like receptor 4 (TLR4) and promote the expression of inflammatory factors (Hayashi and Suzuki, 2015; Xie et al., 2018). Sepsis is closely related to the cascade of cytokines and cytokine storms triggered by pathogen-associated molecular patterns (PAMPs) (Cavaillon, 2018).

A growing number of studies have shown that pyroptosis plays an indispensable role in sepsis. Different from necrosis, pyroptosis undergoes membrane blebbing and produces pyrotic bodies before cell membrane rupture, accompanied with pyknosis and chromatin damage (Chen et al., 2016). Pyroptosis is an inflammatory form of programmed cell death mediated by GSDMD, including caspase-1-mediated canonical pathway and caspase-4/5/11-mediated non-canonical pathway. Inflammasome activates caspase-1/4/5/11, which cleave GSDMD to form honeycomb-like pores on the cell membrane, causing cell swelling and eventually lead to cell rupture and death (Ding et al., 2016). Therefore, inflammasome activation is an important event in the pathogenesis of organ dysfunction in sepsis.

It has been reported that extracellular histones can activate nucleotide-binding oligomerization domain-like receptor protein 3 (NLRP3) inflammasome (Allam et al., 2013), but its mechanism in sepsis pyroptosis is incompletely clear. Histones are important structural elements of nuclear chromatin, while extracellular histones are cytotoxic and can cause immune damage (Allam et al., 2014). Histones can directly activate pattern recognition receptors and indirectly induce cell necrosis to produce local cytokines, thus leading to peritonitis (Allam et al., 2013). In acute lung injury (ALI), extracellular histones are important effectors of tissue damage and inflammation (Bosmann et al., 2013). Circulating histone H3 levels in patients with sepsis are associated with mortality and negatively correlated with antithrombin levels and platelet counts (Wildhagen et al., 2015). Therefore, it is of great significance to explore the role and mechanism of extracellular histones in the pathogenesis of sepsis.

Nucleotide binding oligomerzation domain 2 (NOD2) belongs to the NOD like receptor (NLR) family and are capable of interacting with multiple proteins and modulate immune responses in a stimuli-dependent manner. It has been reported that activated NOD2 can recruit receptor-interacting protein 2 (RIP2), and conducts signal through nuclear factor (NF)- $\kappa \mathrm{B}$ and MAPK pathway (McDonald et al., 2005; Kanneganti et al., 2007). In myocardial ischemia-reperfusion injury, NOD2 promotes myocardial apoptosis by activating NF- $\mathrm{B}$ signaling pathway, and aggravates inflammatory response (Liu et al., 2016). Besides, NOD2 can exacerbate inflammation and podocyte insulin resistance to promote renal injury in diabetic nephropathy ( $\mathrm{Du}$ et al., 2013). V-set and immunoglobulin domain containing 4 (VSIG4), also nominated as complement receptor of the Ig superfamily (CRIg) or Ig superfamily protein 39 (Z39Ig), is a B7 family-related protein. VSIG4 has been confirmed to mediate transcriptional inhibition of NLRP3 (Huang et al., 2019). And expression of VSIG4 attenuates hepatic inflammation and fibrosis in high fat diet (HFD)-induced mice (Li et al., 2019). We wonder if NOD2 and/or VSIG4 involve(s) in pyroptosis induced by extracellular histones.

In this study, we adopted LPS to induce sepsis mice model and LPS or $\mathrm{H} 3$ to induce damage in ANA-1 cell line. NOD2 inhibitor NOD-IN-1 and VSIG4-siRNA were used as interventions to further investigate the mechanism of histone $\mathrm{H} 3$ on pyroptosis in sepsis.

\section{MATERIALS AND METHODS}

\section{Chemicals and Reagents}

RPMI 1640 medium and fetal bovine serum (FBS) were purchased from Gibco (NY, USA). LPS (purity of 99\%, from Escherichia coli O55:B5) was obtained from Sigma (St. Louis, USA, \#L2880). Histone H3 was obtained from Roche Life Science (Stockholm, Sweden). H3 neutralizing antibody was obtained from Abcam (Cambridge, MA, USA, \#ab1791). NODIN-1 (purity of 99\%) was obtained from MCE (USA). VSIG4siRNA was obtained from RiboBio (Guangzhou, China). The antibodies to H3, NLRP3, GSDMD, IL-1 $\beta$, IL-18 were purchased from Cell Signaling Technology (Boston, USA). GAPDH, NOD2, RIP2 antibodies were obtained from Proteintech (Wuhan, China). VSIG4 antibody was obtained from Bioss (Beijing, China). Caspase-1 antibody was obtained from Santa Cruz Biotechnology (Dallas, Texas, USA). Secondary antibodies applied were the goat anti-rabbit/mouse fluorescent antibody purchased from LI-COR Biosciences, Inc. (Lincoln, USA). 
RNAiso Plus, PrimeScript ${ }^{\mathrm{TM}}$ RT reagent kit and SYBR Premix Ex Taq kit were purchased from TaKaRa (Japan). Histone H3 ELISA Kit was obtained from Bioswamp (Wuhan, China). IL-1 $\beta$, IL-18 ELISA Kits were purchased from Elabscience (Wuhan, China).

\section{Cell Culture and Chemical Treatment}

RPMI 1640 medium mixed with $10 \%$ FBS was used to culture ANA-1 cells in an incubator at $37^{\circ} \mathrm{C}, 5 \% \mathrm{CO}_{2}$, and saturated humidity. The macrophages were firstly divided into control group and LPS group. The cells were passed in 6-well plates and cultured to $70 \%$ density. LPS $(10 \mu \mathrm{g} / \mathrm{ml})$ (Le et al., 1998) was used to stimulate the cells. The supernatants were harvested after $24 \mathrm{~h}$ to detect histone $\mathrm{H} 3$ levels. Next the cells were divided into control group and $\mathrm{H} 3$ group. $\mathrm{H} 3(50 \mu \mathrm{g} / \mathrm{ml})$ (Xu et al., 2009) was added into cells. After $12 \mathrm{~h}$, the cells were harvested to detect the expression of related proteins. And then the macrophages were divided into control group, LPS group, LPS + $\mathrm{H} 3$ antibody group. LPS was used to stimulate the cells excluding the control group. H3 antibody $(10 \mu \mathrm{g} / \mathrm{ml})$ (Kang et al., 2014) was added into LPS $+\mathrm{H} 3$ antibody group $2 \mathrm{~h}$ prior to treatment with LPS. The cells were harvested $24 \mathrm{~h}$ after the addition of LPS.

\section{siRNA Transfection}

Cells were seeded in 6-well plates at a density of $5 \times 10^{4}$ cells/well to achieve a confluence of $70 \%$. The macrophages were ultimately divided into control group, $\mathrm{H} 3$ group, $\mathrm{H} 3$ + NOD-IN-1 group, $\mathrm{H} 3$ + VSIG4-siRNA group, H3 + NOD-IN-1 + VSIG4-siRNA group. $\mathrm{H} 3$ was used to stimulate the cells excluding the control group. VSIG4-siRNA transfection was done $24 \mathrm{~h}$ prior to $\mathrm{H} 3$ stimulation and NOD-IN-1 was added into medium $2 \mathrm{~h}$ prior to $\mathrm{H} 3$ stimulation. The cells were harvested $12 \mathrm{~h}$ after the addition of H3. The transfection was done using Lipofectamine 2000 (Invitrogen, USA) according to the manufacturer's instructions. The transfection efficiency was confirmed by quantitative RealTime PCR.

\section{Immunofluorescence}

ANA- 1 cells were seeded in a 24 -well plate $(1.0 \times 104$ cells/well $)$ and allowed to adhere overnight. After stimulation of LPS for $24 \mathrm{~h}$, cells were fixed with $4 \%$ paraformaldehyde for $30 \mathrm{~min}$, permeabilized with $0.2 \%$ Triton X-100 (Beyotime, China) for $20 \mathrm{~min}$, blocked with $5 \%$ bovine serum albumin (BSA, Beijing Solarbio Science and Technology co., ltd.) for $30 \mathrm{~min}$ and incubated with primary antibodies against $\mathrm{H} 3$ (1:100) and NOD2 (1:100) at $4^{\circ} \mathrm{C}$ overnight. The next day, cells were washed and incubated with cy3-labeled fluorescent secondary antibodies (1:100) at room temperature for $1 \mathrm{~h}$. Then the sections were stained with DAPI (Beyotime, China). Observations were performed with a laser scanning confocal microscope (Olympus, Japan, \#FV1200).

\section{Animal Groups}

Male C57BL/6 mice $(n=18)$ specific pathogen-free (SPF) (20$25 \mathrm{~g}$ ) were purchased from Experimental Animal Center of Wuhan University. All animals were acclimatized for 1 week before experimentation and allowed access to food and water freely throughout the acclimatization and experimental periods. They were kept in temperature $\left(22 \pm 2{ }^{\circ} \mathrm{C}\right)$ with a $12 \mathrm{~h}$ light/dark cycle. The mice were randomly divided into three groups: control group, LPS group, LPS $+\mathrm{H} 3$ antibody group. Except for control group, all mice were modeled by intraperitoneal injection with LPS (10 mg/kg) (Kong et al., 2018). The control group mice were given an equal volume of saline. $\mathrm{H} 3$ antibody $(20 \mathrm{mg} / \mathrm{kg})$ (Kang et al., 2014) was given by intraperitoneal injection in LPS $+\mathrm{H} 3$ antibody group $2 \mathrm{~h}$ before sepsis model protocol. All mice were sacrificed under anesthesia after $24 \mathrm{~h}$ when sepsis model established.

\section{Hematoxylin and Eosin (H\&E) and Serum IL-1 $\beta$, IL-18 Levels Detection}

Ten percent neutral-buffered formalin was applied to fix fresh tissue specimens for 2 days. And then tissues were embedded in paraffin, processed for sectioning and staining by H\&E. Tissue sections were assessed under BX 51 light microscope (Olympus, Japan). Serum IL-1 $\beta$, IL-18 levels were detected by ELISA kits according to the manufacturer's instructions.

\section{Quantitative Real-Time PCR}

Total RNAs in ANA-1 cells and tissues were isolated by using RNAiso Plus according to manufacturer's protocol. The cDNAs were produced with a PrimeScript RT reagent kit and incubated at $37^{\circ} \mathrm{C}$ for $15 \mathrm{~min}$ and at $85^{\circ} \mathrm{C}$ for $5 \mathrm{~s}$. Real-time PCRs were performed using a StepOne Plus device (Applied Biosystems) at $95^{\circ} \mathrm{C}$ for $10 \mathrm{~s}$, followed by 40 cycles at $95^{\circ} \mathrm{C}$ for $5 \mathrm{~s}$, and at $60^{\circ} \mathrm{C}$ for $20 \mathrm{~s}$, according to the instructions for the SYBR Premix Ex Taq kit. The data were analyzed by the $2^{-\Delta \Delta C T}$ method. All the primers were synthesized by Tsingke (Wuhan, China), and the sequences are listed in Table $\mathbf{1 .}$

TABLE 1 | The primer sequence for RT-PCR.

\begin{tabular}{lll}
\hline Gene & & Primer sequence $\left(\mathbf{5}^{\prime} \rightarrow \mathbf{3}^{\prime} \mathbf{)}\right.$ \\
\hline GAPDH & Forward & CATCACTGCCACCCAGAAGACTG \\
NLRP3 & Reverse & ATGCCAGTGAGCTCCCGTCAG \\
& Forward & TCACAACTCGCCCAAGGAGGAA \\
GSDMD & Reverse & AAGAGACCACGGCAGAAGCTAG \\
& Forward & GGTGCTTGCTCTGGAGAACTG \\
Caspase-1 & Reverse & GCTGCTTGACAGCACCGTTGT \\
& Forward & GGCACATTCCAGGACTGACTG \\
IL-13 & Reverse & GCAAGACGTGTACGAGTGGTG \\
& Forward & TGGACCTCCAGGATGAGGACA \\
IL-18 & Reverse & GTCATCTCGGAGCCTGTAGTG \\
& Forward & GACAGCCTGTGTCGAGGATATG \\
NOD2 & Reverse & TGTCTTACAGGAGAGGGTAGAC \\
& Forward & CCTAGCACTGATGCTGGAGAAG \\
VSIG4 & Reverse & CGGTAGGTGATGCCATGTGG \\
& Forward & ATGTGAGGTCACCTGGCAGACT \\
& Reverse & GCAGGGTGTAGGTGCTTCAGT
\end{tabular}




\section{Western Blotting}

Proteins from ANA-1 cells and tissues of mice were separated by sodium dodecyl sulfate polyacrylamide gel electrophoresis (SDS-PAGE) and transferred to a PVDF membrane (Millipore, USA). The membranes were incubated with different primary antibodies and secondary antibody. Finally, expression of each protein was detected by Odyssey infrared imaging system. The dilutions of the primary antibodies were as follows: NLRP3, 1:1,000; GSDMD, 1:1,000; IL-1 $\beta, 1: 1,000$; IL-18, 1:1,000; NOD2, $1: 1,000$; RIP2, 1:1,000; VSIG4, 1:1,000; caspase-1, 1:500; and GAPDH, 1:2,000. Membranes were also probed for GAPDH as additional loading controls.

\section{Statistical Analysis}

All statistical analyses were performed using SPSS 25.0. The results were presented as mean \pm SDs. One-way analysis of variance (ANOVA) or Student's $t$-test was applied to examine the differences between groups. $P<0.05$ was considered statistically significant.

\section{RESULTS}

\section{Effect of LPS on Histone H3 in ANA-1 Cells}

The expression of histone $\mathrm{H} 3$ was increased after LPS stimulation. As shown in Figure 1A, the level of extracellular histone $\mathrm{H} 3$ was elevated in LPS group compared with control group $(P<0.05)$. And the expression of cytoplasmic histone $\mathrm{H} 3$ was also increased compared with control group (Figures 1B,C).

\section{Effect of Extracellular Histone $\mathrm{H} 3$ on Pyroptosis in ANA-1 Cells}

Extracellular histone $\mathrm{H} 3$ could cause pyroptosis in ANA-1 cells. As shown in Figures 1D,E, the levels of pyroptosis-related proteins, NLRP3, caspase-1, GSDMD, IL-1 $\beta$, IL-18 were significantly increased compared with control group $(P<0.05)$. Likewise, histone $\mathrm{H} 3$ antibody could partially block LPS-induced pyroptosis. As shown in Figure 2A, compared with control group, the mRNA levels of NLRP3, caspase-1, GSDMD, IL-1 $\beta$, IL-18 were higher in LPS group $(P<0.05)$. While $\mathrm{H} 3$ antibody suppress the mRNA levels of these cytokines $(P<0.05)$. Similarly, as shown in Figures $\mathbf{2 B}-\mathbf{D}$, the western blotting showed that protein levels of NLRP3, caspase-1, GSDMD, IL-1 $\beta$, IL-18 were increased compared with control group $(P<0.05)$. Whereas, $\mathrm{H} 3$ antibody suppress the expression of these proteins $(P<0.05)$. These results confirmed that LPS could induce the release of histone $\mathrm{H} 3$, which could cause pyroptosis in ANA-1 macrophages.

\section{Effect of Histone H3 on NOD2 and VSIG4 Signal Transduction in ANA-1 Cells}

It has been reported that NOD2 can regulate inflammation and apoptosis (Liu et al., 2016; Panda and Gekara, 2018). And VSIG4 has been confirmed to mediate transcriptional inhibition of NLRP3, macrophages lacking VSIG4 exacerbate pyroptosis in response to NLRP3 inflammasome stimuli (Huang et al., 2019). So we wonder if NOD2 and VSIG4 involve in pyroptosis induced by extracellular histone. As shown in Figures 3A,B, the expression of NOD2 was elevated in H3 group compared with control group $(P<0.05)$. Besides, the protein level of RIP2 was also up-regulated in LPS group $(P<0.05)$ but down-regulated by H3 antibody $(P<0.05)$. However, LPS inhibited the expression of VSIG4 $(P<0.05)$ and suppression of $\mathrm{H} 3$ promoted the protein level of VSIG4 $(P<0.05)$ (Figures 3C-E). These results indicated that NOD2 and VSIG4 were involved in pyroptosis.

\section{The Relationship Between NOD2 and VSIG4 in ANA-1 Cells}

In order to find out whether there is a connection between NOD2 and VSIG4, we used NOD2 inhibitor NOD-IN-1 and VSIG4-siRNA in histone $\mathrm{H} 3$ stimulated ANA-1 macrophages. As shown in Figure 4A, the mRNA level of NOD2 in H3 group was higher compared with control group $(P<0.05)$, but there is no statistical significance between $\mathrm{H} 3$ group and VSIG4-siRNA group $(P>0.05)$. Also, the mRNA level of NOD2 in NOD-IN-1 group and NOD-IN-1 + VSIG4-siRNA group had no statistical significance $(P>0.05)$. On the contrary, the mRNA expression of VSIG4 in $\mathrm{H} 3$ group was decreased compared with control group $(P<0.05)$, but up-regulated by NOD-IN-1 $(P<0.05)$. Besides, the mRNA level of VSIG4 in NOD-IN-1 + VSIG4siRNA group was elevated compared with VSIG4-siRNA group $(P<0.05)$. The western blotting showed the similarly results (Figures 4B-D). Pyroptosis was also assessed using NOD-IN-1 and VSIG4-siRNA (Figures 4B-D), the western blotting showed that the protein levels of NLRP3, caspase-1, GSDMD, IL-1 $\beta$, IL18 were decreased in NOD-IN-1 group compared with $\mathrm{H} 3$ group $(P<0.05)$, while these protein levels were elevated in VSIG4siRNA group compared with $\mathrm{H} 3$ group $(P<0.05)$. These results further confirmed the effect of NOD2 and VSIG4 on pyroptosis.

\section{Histone H3 Antibody Improved Survival Rate and Alleviated Histological Changes in Mice}

After $24 \mathrm{~h}$, the mice in control group were all alive, and the survival rate of LPS $+\mathrm{H} 3$ antibody group (4 of 6) was significantly higher than that of LPS group (1 of 6). As H\&E staining shown in Figure 5, the liver lobule structure in control group was clear and complete, and the liver cell morphology was normal, without necrosis and infiltration of inflammatory cells. In LPS group, the liver tissue structure was seriously destroyed, with extensive necrosis and large amount of inflammatory cells infiltration. While the hepatic lobule structure in LPS $+\mathrm{H} 3$ antibody group mice was clearer than that in LPS group, and the infiltration of inflammatory cells and necrotic hepatocytes were also reduced. Besides, the histologic analysis of intestine revealed that intestine mucosal was damaged in LPS group, with denuding and loss of villi, and large reactive lymphoid follicles along with excess of lymphocytes infiltration. However, the damages of intestine were alleviated by $\mathrm{H} 3$ antibody. The pathological changes of lung were also assessed. The lung tissues of control group exhibited normal structure. LPS significantly caused lung pathological damage, including edema, pulmonary congestion, neutrophils infiltration, and airway alveolar disarray. Whereas, intervention of H3 antibody inhibited LPS induced 
A

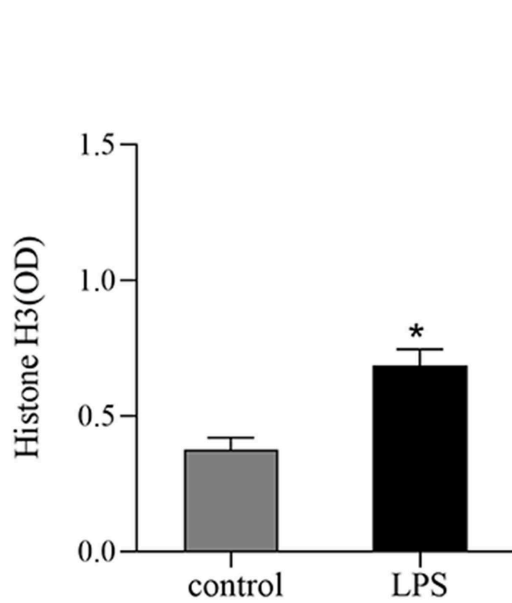

C

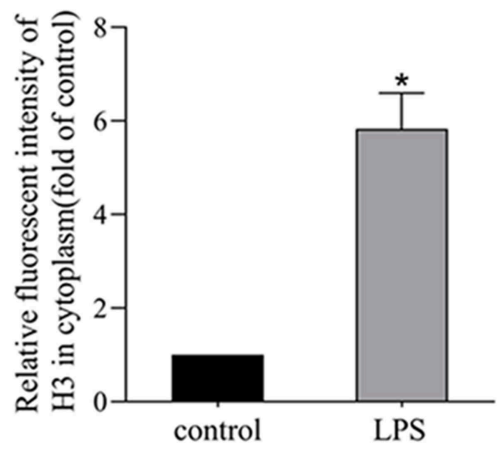

B
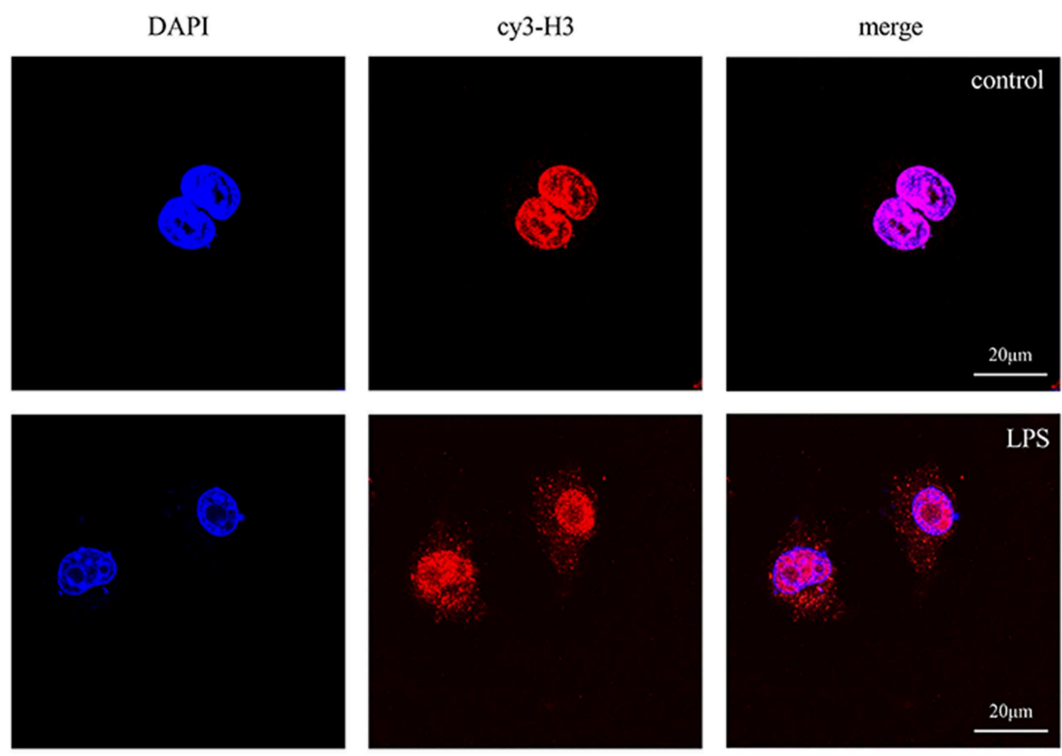

D

E

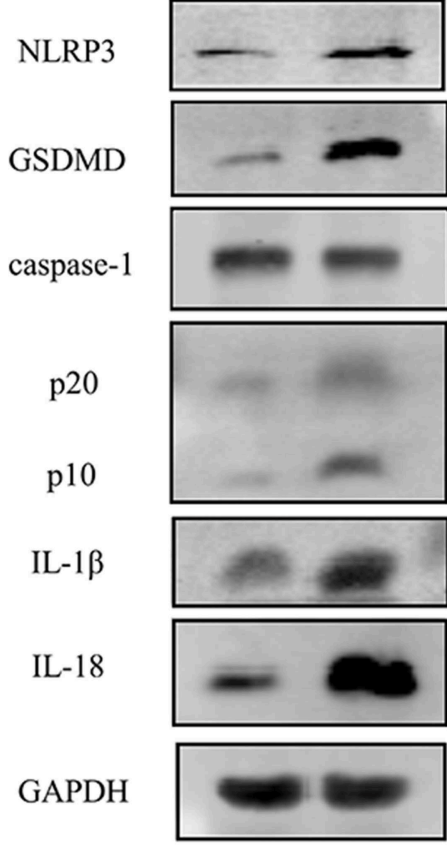

control
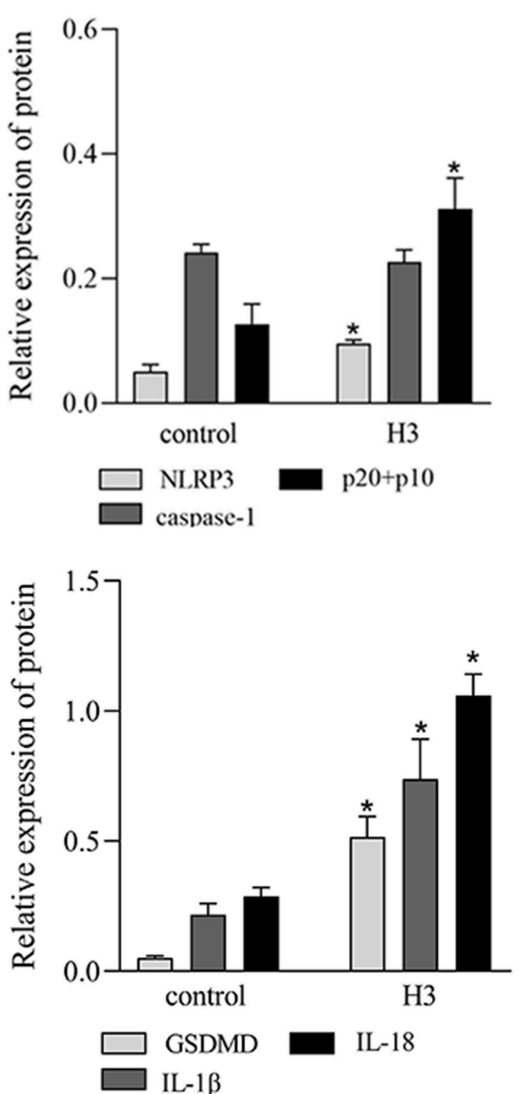

FIGURE 1 | LPS stimulated the release of histone $\mathrm{H} 3$ and $\mathrm{H} 3$ induced pyroptosis in vitro. Cells were stimulated with $\mathrm{LPS}(10 \mu \mathrm{g} / \mathrm{ml})$ for $24 \mathrm{~h}$ or histone $\mathrm{H} 3(50 \mu \mathrm{g} / \mathrm{ml})$ for $12 \mathrm{~h}$. (A) ELISA results of histone $\mathrm{H} 3$ in cell supernatant. (B,C) Immunofluorescence was used to detect the expression of histone $\mathrm{H} 3$ in cytoplasm. Relative fluorescent intensity of histone $\mathrm{H} 3$ in cytoplasm was presented as mean \pm SDs of three independent experiments. (D,E) Effects of histone H3 on NLRP3, caspase-1, GSDMD, IL-1 $\beta$, IL-18 protein levels in ANA-1 cells. Odyssey was used to calculate the grayscale of each strip and the results (relative expression to GAPDH) were presented as mean \pm SDs based on three repetitions. ${ }^{\star} P<0.05$, compared with control group. 


\section{A}

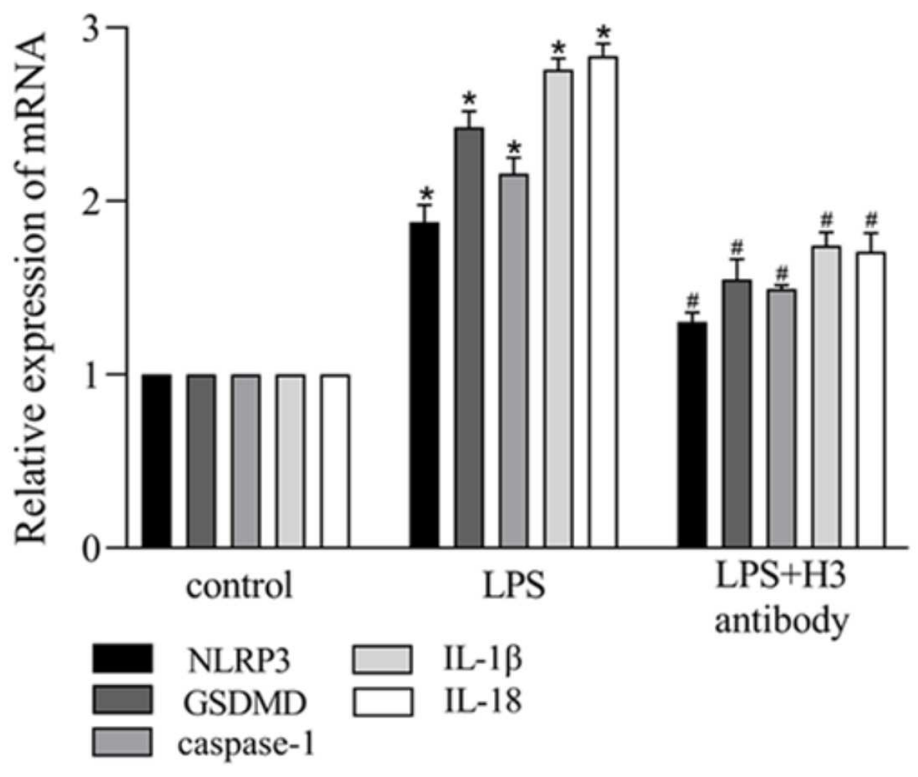

B

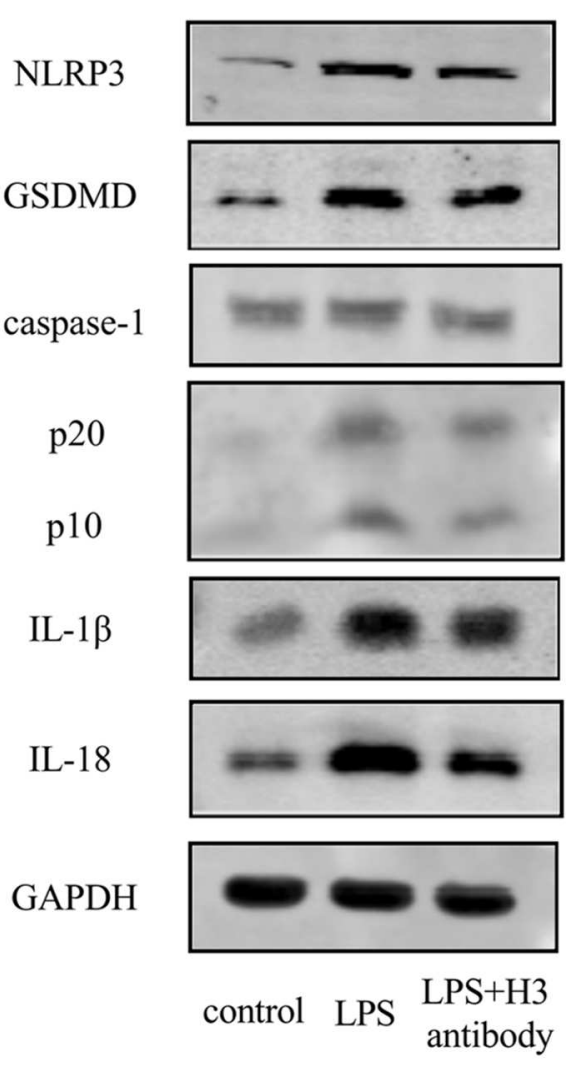

C

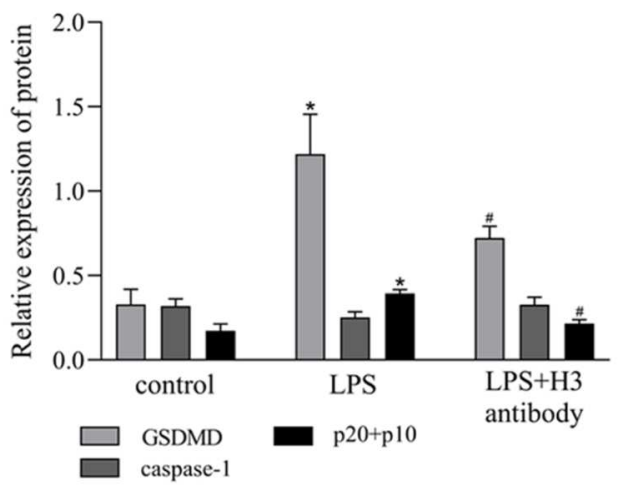

D

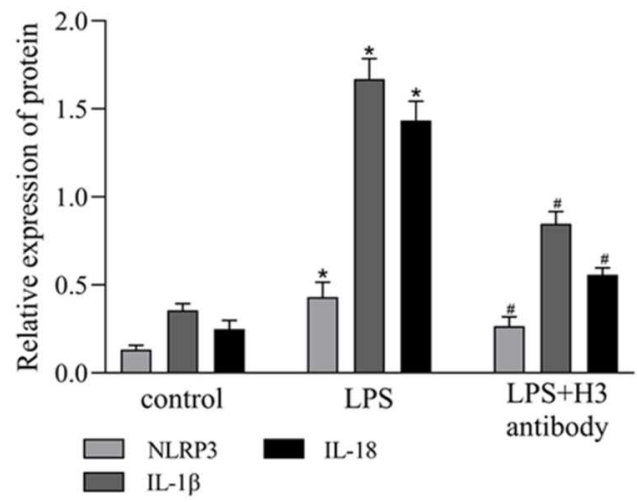

FIGURE 2 | Histone H3 antibody attenuated pyroptosis induced by LPS in vitro. LPS (10 $\mu \mathrm{g} / \mathrm{ml})$ was used to stimulate the cells excluding control group. H3 antibody $(10 \mu \mathrm{g} / \mathrm{ml})$ was added into LPS $+\mathrm{H} 3$ antibody group $2 \mathrm{~h}$ prior to LPS. The cells were harvested $24 \mathrm{~h}$ after the addition of LPS. (A) The mRNA expression (relative to GAPDH) of NLRP3, caspase-1, GSDMD, IL-1 $\beta$, IL-18 in ANA-1 cells. (B-D) The protein levels of NLRP3, caspase-1, GSDMD, IL-1 $\beta$, IL-18 in ANA-1 cells. Results were presented as mean \pm SDs of three repetitions. ${ }^{*} P<0.05$, compared with control group; $\# P<0.05$, compared with LPS group. 
A

DAPI
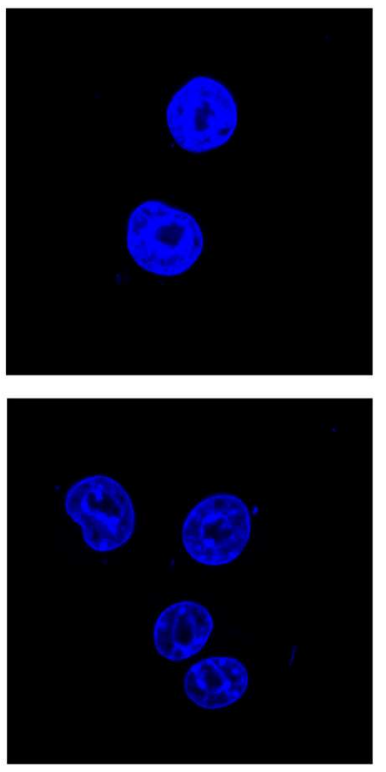

cy3-NOD2
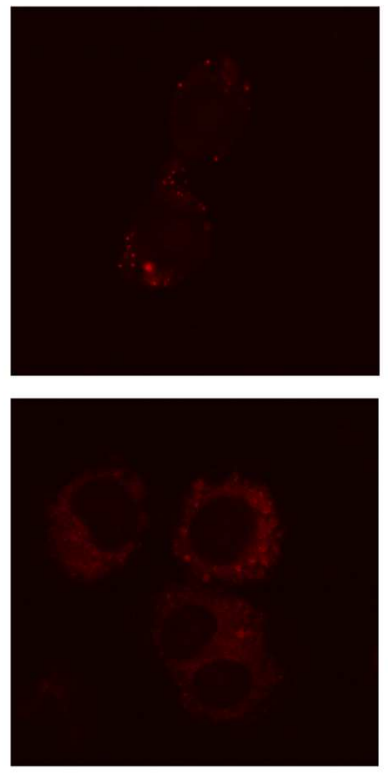

B

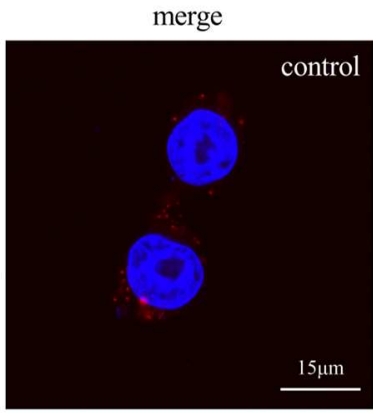

H3

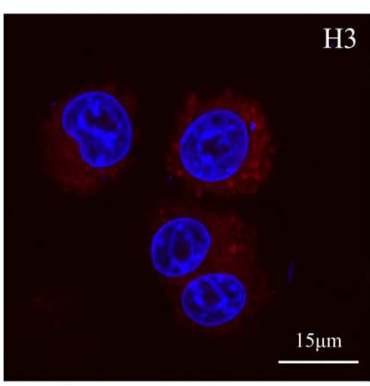

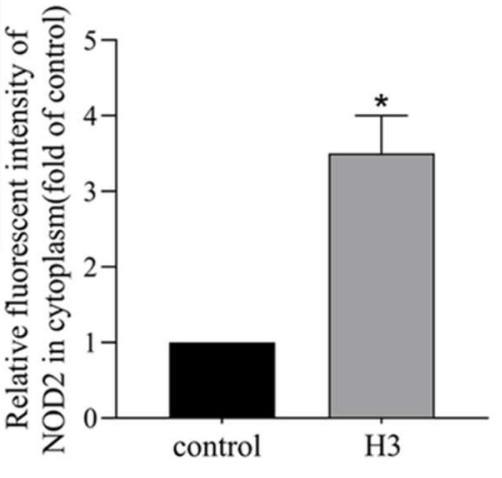

C

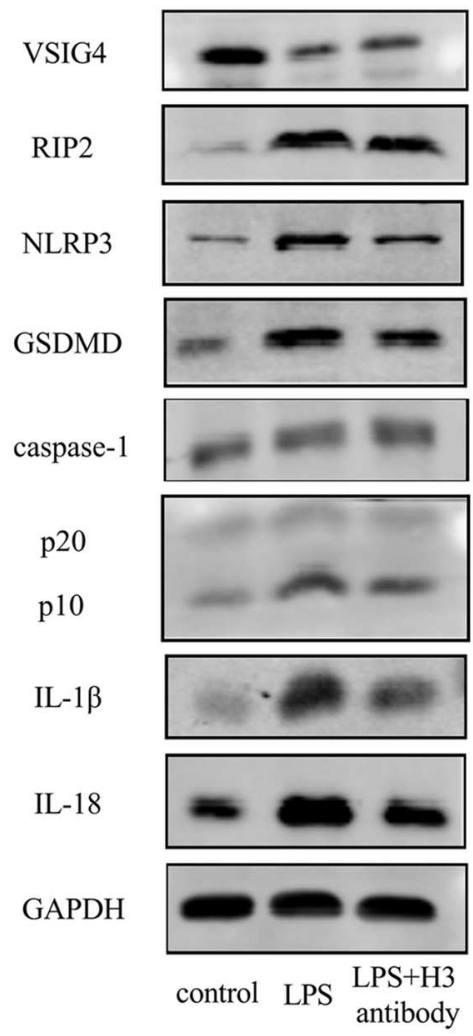

D

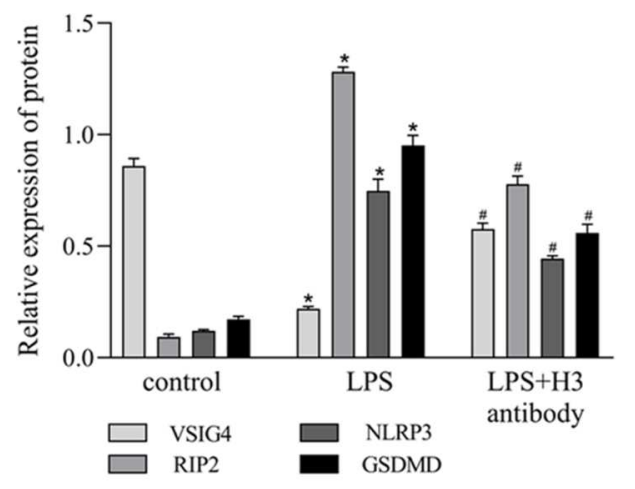

E

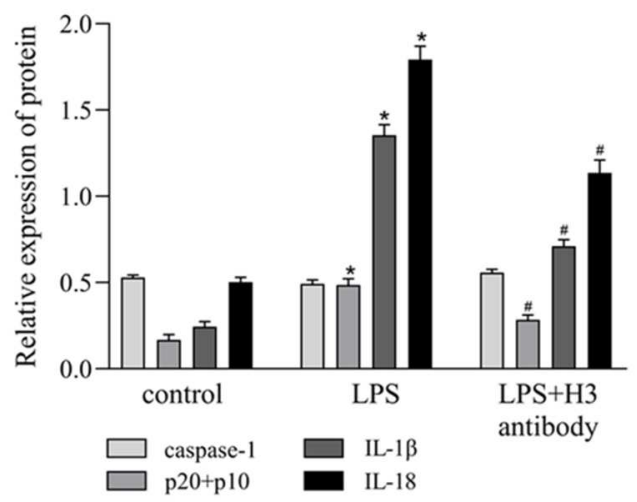

FIGURE 3 | Effects of Histone H3 antibody on LPS-induced NOD2 and VSIG4 signal transduction in vitro. Cells were treated the same way as Figure 2. (A,B) Immunofluorescence was used to detect the expression of NOD2 in cytoplasm. Relative fluorescent intensity of NOD2 in cytoplasm was presented as mean \pm SDs of three independent experiments. (C-E) The protein levels of RIP2, VSIG4, NLRP3, caspase-1, GSDMD, IL-1 $\beta$, IL-18 in ANA-1 cells. Results were presented as mean \pm SDs of three repetitions. ${ }^{*} P<0.05$, compared with control group; $\# P<0.05$, compared with LPS group. 
A
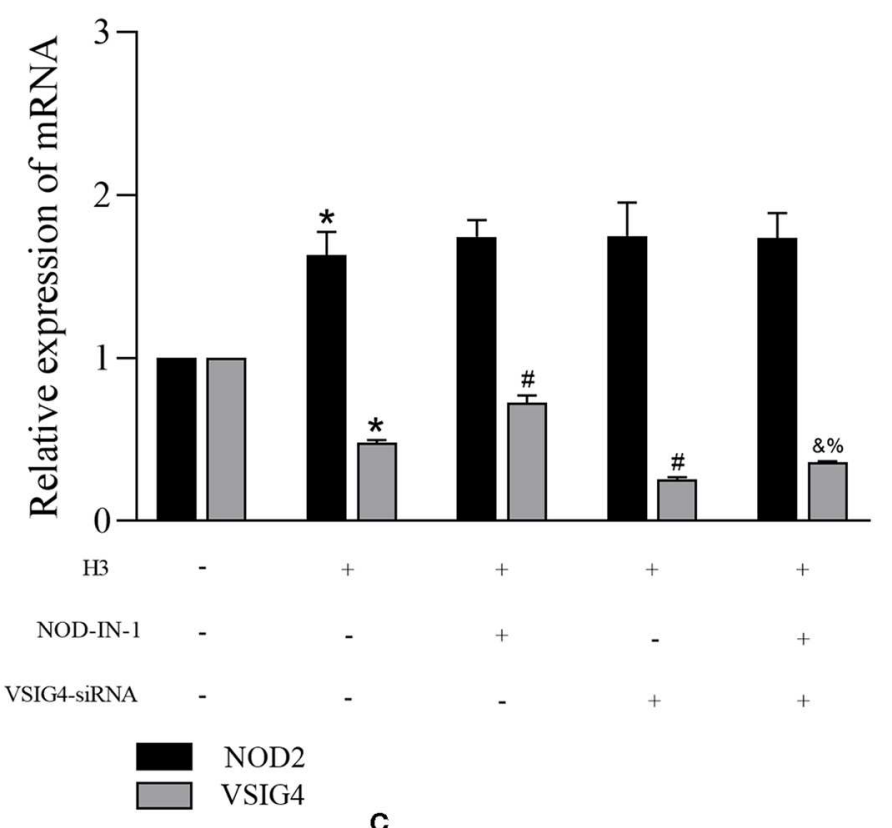

B

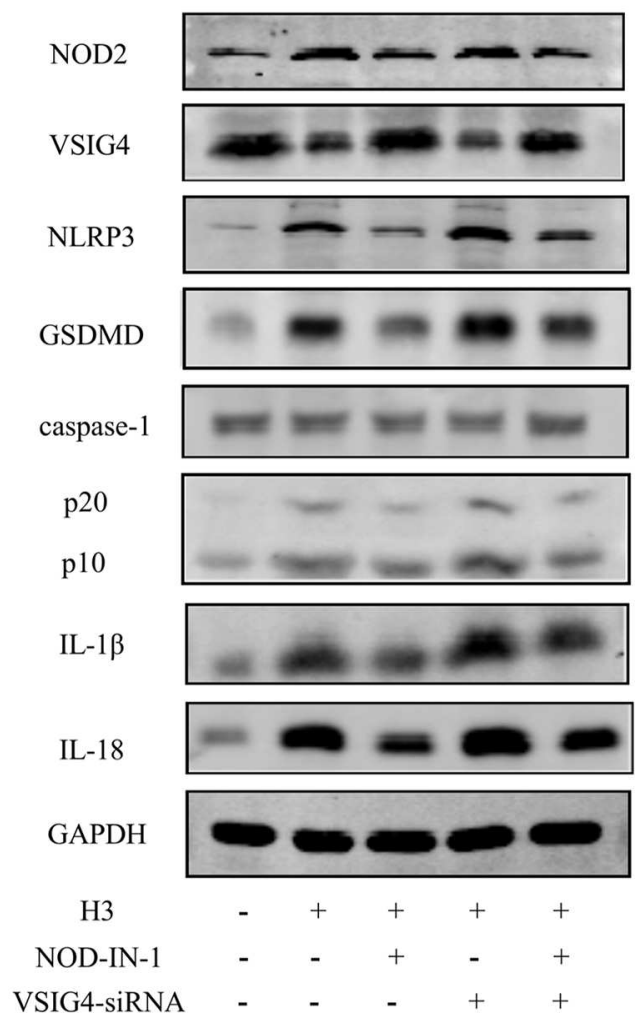

C

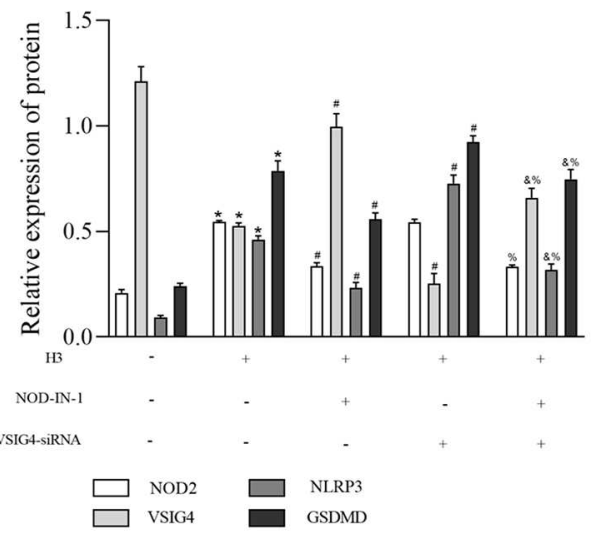

D

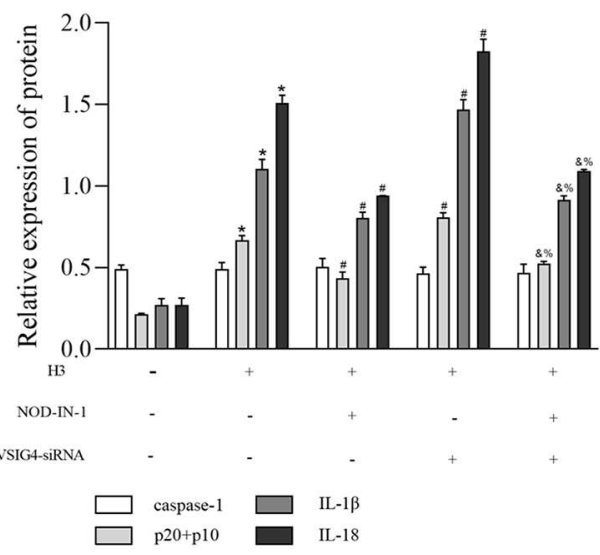

FIGURE 4 | The relationship between NOD2 and VSIG4 and the effect of NOD-IN-1, VSIG4-siRNA on pyroptosis in vitro. Histone H3 was used to stimulate cells excluding the control group. VSIG4-siRNA transfection was done $24 \mathrm{~h}$ prior to $\mathrm{H} 3$ stimulation and NOD-IN-1 was added into medium $2 \mathrm{~h}$ prior to H3 stimulation. The cells were harvested $12 \mathrm{~h}$ after the addition of H3. (A) The mRNA expression (relative to GAPDH) of NOD2, VSIG4 in each group. (B-D) The protein expression of NOD2, VSIG4, NLRP3, caspase-1, GSDMD, IL-1 $\beta$, IL-18 in each group. Results were presented as mean \pm SDs of three repetitions. ${ }^{*} P<0.05$, compared with control group; $\# P<0.05$, compared with H3 group; ${ }^{\&} P<0.05$, compared with NOD-IN-1 group; ${ }^{\%} P<0.05$, compared with VSIG4-siRNA group. 


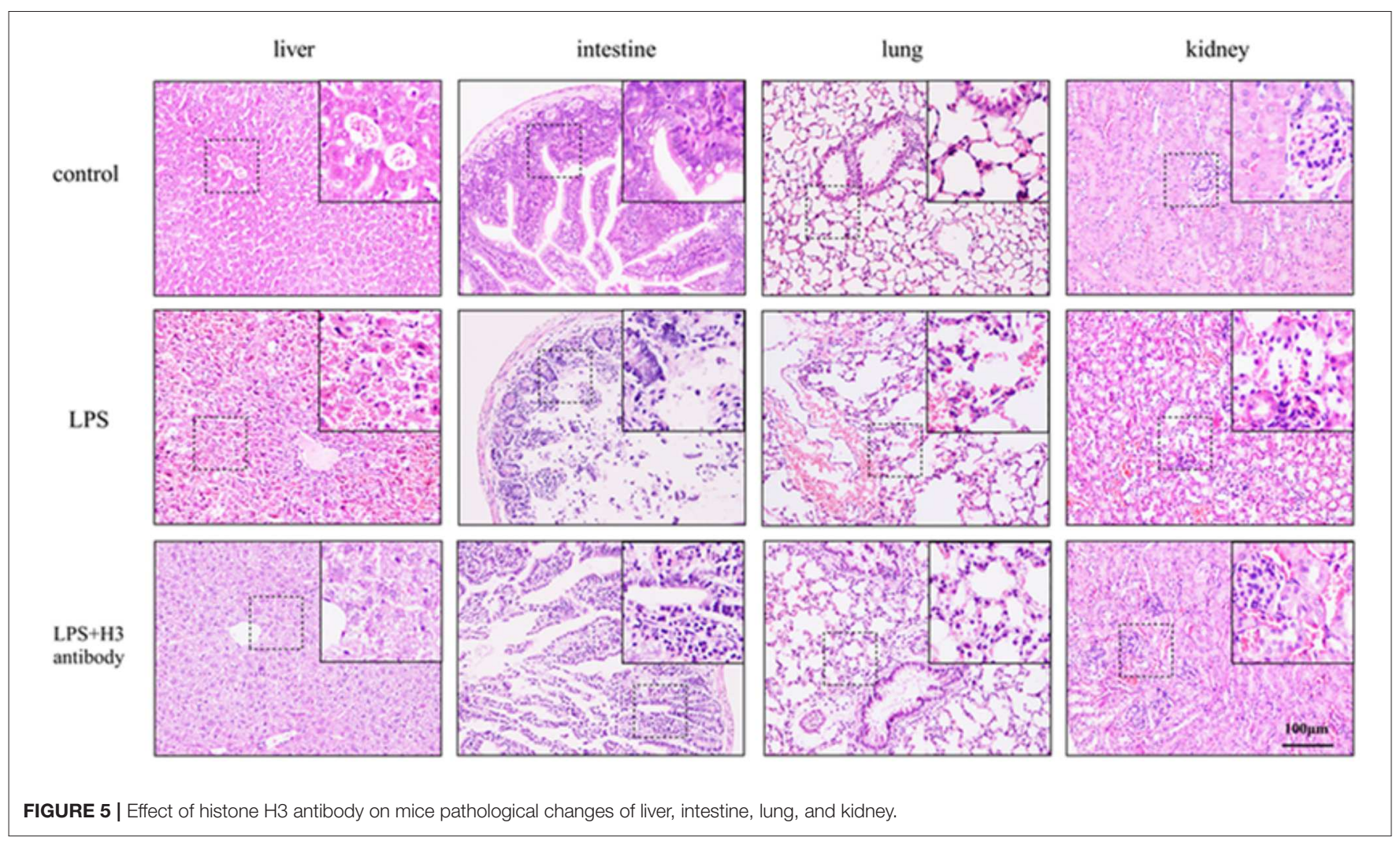

lung pathological changes. Moreover, the histological damages of kidney caused by LPS, including mesangial cells proliferation, inflammatory cells infiltration and even necrosis, were alleviated by $\mathrm{H} 3$ antibody.

\section{Histone H3 Antibody Alleviated Pyroptosis Induced by LPS Through NOD2 and VSIG4 Pathways in Mice}

As shown in Figures 6A,B, the serum expression of IL-1 $\beta$, IL-18 in LPS group was significantly increased compared with control group $(P<0.05)$, but decreased by $\mathrm{H} 3$ antibody $(P<0.05)$. The protein levels of NOD2, RIP2, NLRP3, caspase-1 were visibly up-regulated and VSIG4 was decreased in liver, intestine, lung and kidney stimulated by LPS $(P<0.05)$. Whereas, H3 antibody reduced the protein levels of NOD2, RIP2, NLRP3, caspase1 , and up-regulated the protein level of VSIG4 $(P<0.05)$ (Figures 6C-K).

\section{DISCUSSION}

Sepsis is a major cause of deaths among hospitalized patients worldwide, and the disease progresses rapidly. Despite the current excellent clinical treatments and care measures, the incidence and mortality of sepsis remain high. LPS is the main stimulant of sepsis, which has extensive biological activities and can activate monocytes, macrophages, causing the release of a variety of inflammatory mediators, leading to pathological physiological changes (Cinel and Opal, 2009). The pathophysiological mechanism of sepsis is very complex, including inflammation, immune and coagulation dysfunction and other aspects, involving changes in cell function, metabolism, and microcirculation. In the early stage, sepsis is mainly manifested as excessive inflammatory response. Cytokines, immune system and coagulation system dysfunction lead to vascular endothelial permeability increased, tissue edema, and finally microthrombus, shock, and organ failure. In late period, the main manifestation is excessive immune suppression, which seriously declines the body's resistance and immunity, and finally causes the body to suffer more serious damages (Anas et al., 2010).

The role of pyroptosis activated by inflammasome in sepsis has been reported (Guo et al., 2015; Kim et al., 2016). In sepsis, pyroptosis is necessary to $\mathrm{f}$ resist bacterial infection, but excessive pyroptosis can aggravate the inflammatory response. As pathogens and toxins invade the body, they are recognized by pattern recognition receptors, promoting the assembly of inflammasome, activating caspase-1, inducing the maturation and secretion of inflammatory cytokines IL-1 $\beta$ and IL-18, and leading to cell pyroptosis (Kumar, 2018). The activation of inflammasome NLRP3 can lead to massive infiltration of neutrophils and macrophages in liver, kidney, and other organs, and then induce cell pyroptosis (Wu et al., 2015). LPS can also directly bind and activate caspase-11 to induce cell pyroptosis, and simultaneously activate NLRP3 inflammasome, mediate the maturation and secretion of IL-1 and IL-18, and 
A

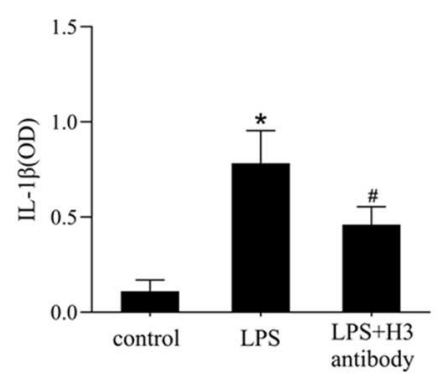

B

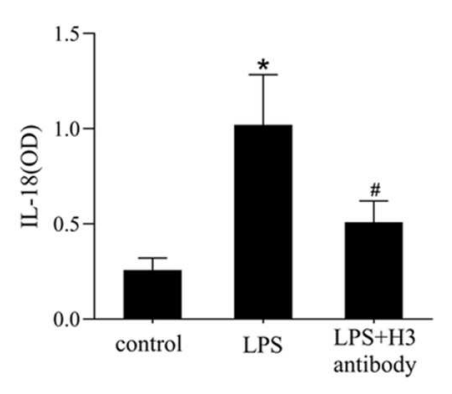

D

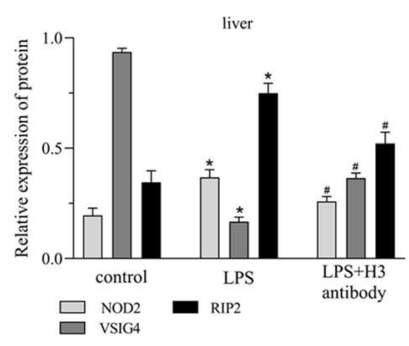

H

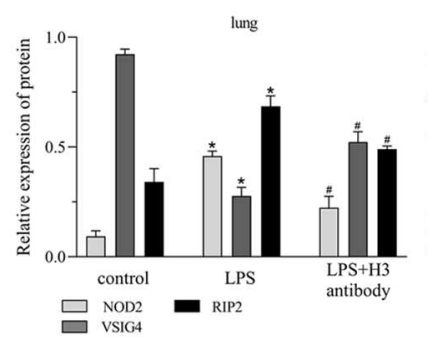

$\mathbf{E}$ c
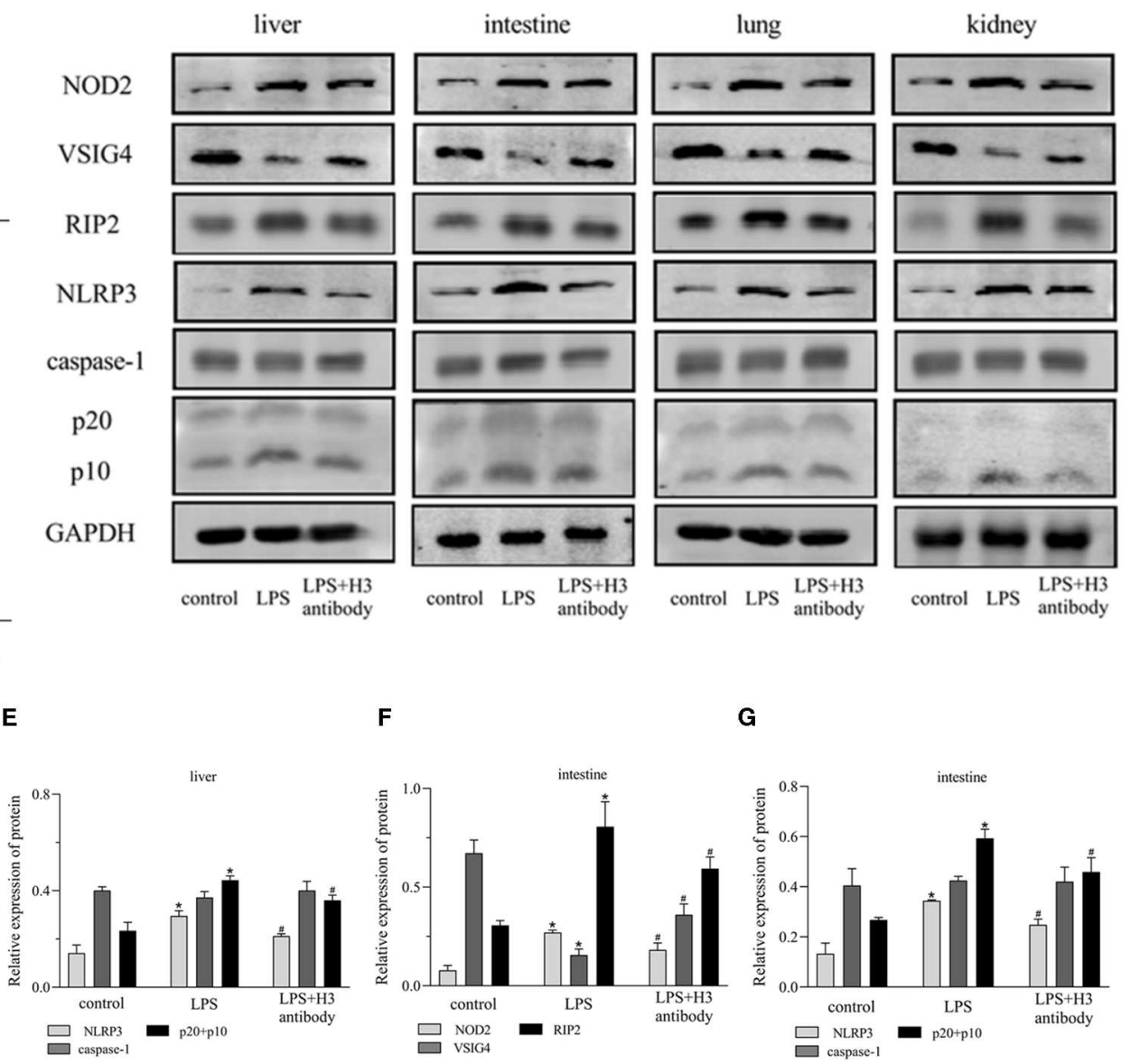

$\mathbf{F}$

G
I

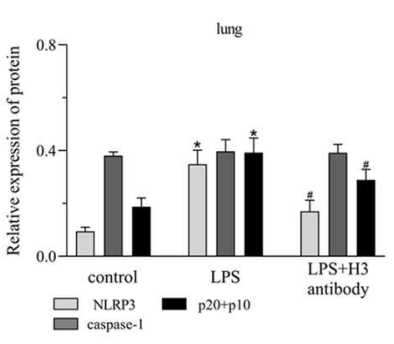

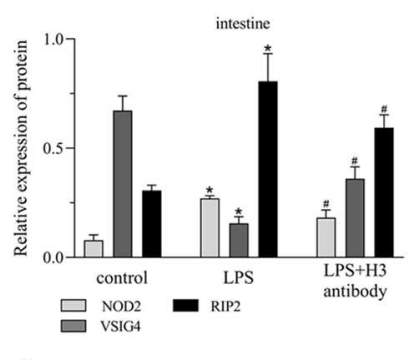

J

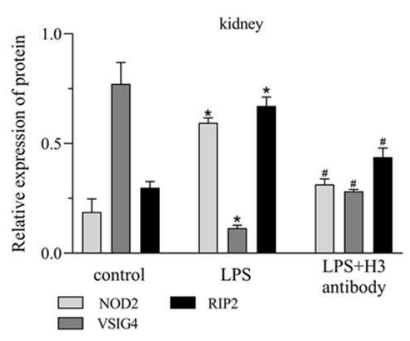

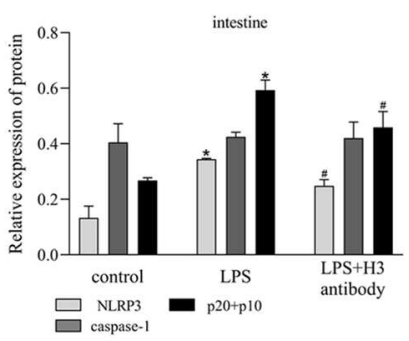

K

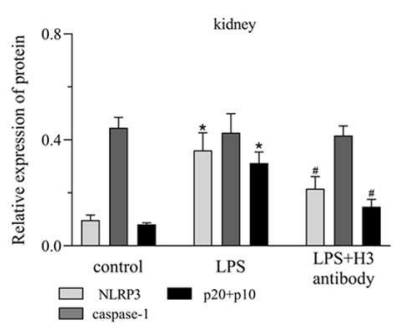

FIGURE 6 | Effect of histone H3 antibody on NOD2, VSIG4, and pyroptosis in mice. All mice were modeled by LPS (10 mg/kg) except for control group. H3 antibody $(20 \mathrm{mg} / \mathrm{kg})$ was given in LPS + H3 antibody group $2 \mathrm{~h}$ before sepsis model protocol. All mice were sacrificed after $24 \mathrm{~h}$. (A,B) ELISA results of IL-1 $\beta$, IL-18 in mice serum. (C-K) Effect of histone H3 antibody on NOD2, RIP2, VSIG4, NLRP3, caspase-1 protein levels in liver, intestine, lung, and kidney. Results were presented as mean \pm SDs of three repetitions. ${ }^{*} P<0.05$, compared with control group; $\# P<0.05$, compared with LPS group.

further release damage associated molecular pattern molecules (DAMPs), such as high mobility group box-1 (HMGB1), which have an important impact on the development of sepsis (Shi et al., 2014).

Extracellular histones, which have been reported to activate NLRP3 inflammasome (Allam et al., 2013), are associated with a variety of inflammation and diseases. And it has been reported that neutrophil extracellular traps (NETs), in which histone H3 is a key component, can promote macrophage pyroptosis in sepsis (Chen et al., 2018). Once released from the nucleosome, extracellular histones exert their damaging effects in three ways: (1) induce chemokine release or act as chemokines; (2) by 
inducing cytokine release and/or apoptosis of adjacent cells and leukocytes; (3) through direct cytotoxicity (Szatmary et al., 2018). Extracellular histones can interact with TLR2, TLR4 (Allam et al., 2012) and TLR9 (Huang et al., 2011) to cause organ damages in acute kidney injury and sterile inflammatory liver injury. Moreover, circulation histones are elevated in acute pancreatitis, and are correlated negatively with leucocyte cell viability (Liu et al., 2017). So we wonder whether histones change in sepsis, and how histones are related to pyroptosis.

In our experiments, LPS was used to stimulate macrophages. The results showed that the level of histone $\mathrm{H} 3$ was increased after LPS stimulation. Furthermore, when stimulated with histone H3, pyroptosis-related proteins, NLRP3, caspase-1, GSDMD, IL-1 $\beta$, IL-18 increased. And cell pyroptosis caused by LPS could be inhibited by $\mathrm{H} 3$ antibody. These results indicated that extracellular histone $\mathrm{H} 3$ induced by LPS could cause pyroptosis in macrophages. To further explore the mechanisms of histone $\mathrm{H} 3$ on pyroptosis, we evaluated the effect of histone H3 on NOD2 and VSIG4 signaling pathways. Our results showed that the expression of NOD2 and RIP2 was elevated compared with control group. However, the expression of VSIG4 was inhibited by LPS and suppression of H3 promoted the protein level of VSIG4. The similar results were also observed in animals. The tissue structures of liver, intestine, lung, and kidney were seriously destroyed by LPS, whereas, inhibition of $\mathrm{H} 3$ alleviated the damages induced by LPS. And the protein levels of NOD2, RIP2 were up-regulated in sepsis mice but down-regulated when H3 was suppressed. On contrary, VSIG4 was down-regulated in sepsis mice but up-regulated by $\mathrm{H} 3$ antibody. These results revealed that histone $\mathrm{H} 3$ could cause pyroptosis through NOD2RIP2 and VSIG4 signal pathways.

In order to find out whether there was a connection between NOD2 and VSIG4, NOD2 inhibitor and VSIG4-siRNA was used in histone $\mathrm{H} 3$ stimulated ANA-1 macrophages. NOD2 and NLRP3 are both involved in pyroptosis, and VSIG4 has been verified to suppress NLRP3 (Huang et al., 2019), our results showed that NOD2 could negatively regulate VSIG4 and positively regulate NLRP3; while VSIG4 had a slight effect

\section{REFERENCES}

Allam, R., Darisipudi, M. N., Tschopp, J., and Anders, H. J. (2013). Histones trigger sterile inflammation by activating the NLRP3 inflammasome. Eur. J. Immunol. 43, 3336-3342. doi: 10.1002/eji.201243224

Allam, R., Kumar, S. V., Darisipudi, M. N., and Anders, H. J. (2014). Extracellular histones in tissue injury and inflammation. J. Mol. Med. 92, 465-472. doi: 10.1007/s00109-014-1148-z

Allam, R., Scherbaum, C. R., Darisipudi, M. N., Mulay, S. R., Hagele, H., Lichtnekert, J., et al. (2012). Histones from dying renal cells aggravate kidney injury via TLR2 and TLR4. J. Am. Soc. Nephrol. 23, 1375-1388. doi: 10.1681/ASN.2011111077

Anas, A. A., Wiersinga, W. J., de Vos, A. F., and van der Poll, T. (2010). Recent insights into the pathogenesis of bacterial sepsis. Neth. J. Med. 68, 147-152. doi: 10.1038/bjc.1996.252

Bosmann, M., Grailer, J. J., Ruemmler, R., Russkamp, N. F., Zetoune, F. S., Sarma, J. V., et al. (2013). Extracellular histones are essential effectors of C5aR- and C5L2-mediated tissue damage and inflammation in acute lung injury. FASEB J. 27, 5010-5021. doi: 10.1096/fj.13-236380 on NOD2 and down-regulated NLRP3. These results indicated that NOD2 is a bridge molecule between VSIG4 and NLRP3. Due to limitation of experimental conditions, the specific regulatory relationship between NOD2 and VSIG4 needs further experiments to verify.

In conclusion, extracellular histone $\mathrm{H} 3$ induced by LPS could cause pyroptosis during sepsis. The mechanism of extracellular histone $\mathrm{H} 3$ on pyroptosis was partly via NOD2 and VSIG4/NLRP3 pathways. The present study not only proved that extracellular histone $\mathrm{H} 3$ aggravated inflammation as we previously speculate but also further demonstrated its mechanism on pyroptosis. This experiment provides a new direction of prevention and treatment for sepsis.

\section{DATA AVAILABILITY STATEMENT}

All datasets generated for this study are included in the article/supplementary material.

\section{ETHICS STATEMENT}

This animal study was reviewed and approved by Ethics Committee of Renmin Hospital of Wuhan University.

\section{AUTHOR CONTRIBUTIONS}

ZG contributed to study conceptualization, supervision and reviewed, and edited the manuscript. CS designed the experiments, analyzed the data, and wrote the paper. YW, QC, FJ, and MP performed the experiments and contributed reagents, materials, and analysis tools. All authors approved the final version of the manuscript.

\section{FUNDING}

This work was supported by the National Natural Science Foundation of China (81870413). 
Gao, Y. L., Yu, M. M., Shou, S. T., Yao, Y., Liu, Y. C., Wang, L. J., et al. (2016). Tuftsin prevents the negative immunoregulation of neuropilin1highCD4+CD25+Regulatory $\mathrm{T}$ cells and improves survival rate in septic mice. Oncotarget 7, 81791-81805. doi: 10.18632/oncotarget.13235

Guo, H., Callaway, J. B., and Ting, J. P. (2015). Inflammasomes: mechanism of action, role in disease, and therapeutics. Nat. Med. 21, 677-687. doi: $10.1038 / \mathrm{nm} .3893$

Hayashi, T., and Suzuki, K. (2015). Changes of expression of the protein C pathway components in LPS-induced endotoxemia-implication for sepsis. Cardiovasc. Hematol. Disord. Drug Targets 15, 2-9. doi: 10.2174/1871529X15666150108110821

Huang, H., Evankovich, J., Yan, W., Nace, G., Zhang, L., Ross, M., et al. (2011). Endogenous histones function as alarmins in sterile inflammatory liver injury through Toll-like receptor 9 in mice. Hepatology 54, 999-1008. doi: 10.1002/hep. 24501

Huang, X., Feng, Z., Jiang, Y., Li, J., Xiang, Q., Guo, S., et al. (2019). VSIG4 mediates transcriptional inhibition of Nlrp3 and Il-1beta in macrophages. Sci. Adv. 5:eaau7426. doi: 10.1126/sciadv.aau7426

Kang, R., Zhang, Q., Hou, W., Yan, Z., Chen, R., Bonaroti, J., et al. (2014). Intracellular Hmgb1 inhibits inflammatory nucleosome release and limits acute pancreatitis in mice. Gastroenterology 146, 1097-1107. doi: 10.1053/j.gastro.2013.12.015

Kanneganti, T. D., Lamkanfi, M., and Nunez, G. (2007). Intracellular NOD-like receptors in host defense and disease. Immunity 27, 549-559. doi: 10.1016/j.immuni.2007.10.002

Kim, M. J., Bae, S. H., Ryu, J. C., Kwon, Y., Oh, J. H., Kwon, J., et al. (2016). SESN2/sestrin2 suppresses sepsis by inducing mitophagy and inhibiting NLRP3 activation in macrophages. Autophagy 12, 1272-1291. doi: 10.1080/15548627.2016.1183081

Kong, W., Kang, K., Gao, Y., Liu, H., Meng, X., Cao, Y., et al. (2018). GTS21 Protected against LPS-induced Sepsis myocardial injury in mice through alpha7nAChR. Inflammation 41, 1073-1083. doi: 10.1007/s10753-018-0759-x

Kumar, V. (2018). Inflammasomes: pandora's box for sepsis. J. Inflamm. Res. 11, 477-502. doi: 10.2147/JIR.S178084

Le, Q., Daniel, R., Chung, S. W., Kang, A. D., Eisenstein, T. K., Sultzer, B. M., et al. (1998). Involvement of C-Abl tyrosine kinase in lipopolysaccharide-induced macrophage activation. J. Immunol. 160, 3330-3336.

Li, Y., Sun, J. P., Wang, J., Lu, W. H., Xie, L. Y., Lv, J., et al. (2019). Expression of Vsig4 attenuates macrophage-mediated hepatic inflammation and fibrosis in high fat diet (HFD)-induced mice. Biochem. Biophys. Res. Commun. 516, 858-865. doi: 10.1016/j.bbrc.2019.06.045

Liu, L., and Sun, B. (2019). Neutrophil pyroptosis: new perspectives on sepsis. Cell. Mol. Life Sci. 76, 2031-2042. doi: 10.1007/s00018-019-0 3060-1

Liu, T., Huang, W., Szatmary, P., Abrams, S. T., Alhamdi, Y., Lin, Z., et al. (2017). Accuracy of circulating histones in predicting persistent organ failure and mortality in patients with acute pancreatitis. Br. J. Surg. 104, 1215-1225. doi: $10.1002 /$ bjs. 10538
Liu, Y., Yang, H., Liu, L. X., Yan, W., Guo, H. J., Li, W. J., et al. (2016). NOD2 contributes to myocardial ischemia/reperfusion injury by regulating cardiomyocyte apoptosis and inflammation. Life Sci. 149, 10-17. doi: 10.1016/j.lfs.2016.02.039

McDonald, C., Chen, F. F., Ollendorff, V., Ogura, Y., Marchetto, S., Lecine, P., et al. (2005). A role for Erbin in the regulation of Nod2-dependent NF-kappaB signaling. J. Biol. Chem. 280, 40301-40309. doi: 10.1074/jbc.M508538200

Panda, S., and Gekara, N. O. (2018). The deubiquitinase MYSM1 dampens NOD2mediated inflammation and tissue damage by inactivating the RIP2 complex. Nat Commun. 9:4654. doi: 10.1038/s41467-018-07016-0

Rhodes, A., Evans, L. E., Alhazzani, W., Levy, M. M., Antonelli, M., Ferrer, R., et al. (2017). Surviving Sepsis campaign: international guidelines for management of Sepsis and septic shock: 2016. Intensive Care. Med. 43, 304-377. doi: 10.1007/s00134-017-4683-6

Shi, J., Zhao, Y., Wang, Y., Gao, W., Ding, J., Li, P., et al. (2014). Inflammatory caspases are innate immune receptors for intracellular LPS. Nature 514, 187-192. doi: 10.1038/nature13683

Szatmary, P., Huang, W., Criddle, D., Tepikin, A., and Sutton, R. (2018). Biology, role and therapeutic potential of circulating histones in acute inflammatory disorders. J. Cell. Mol. Med. 22, 4617-4629. doi: 10.1111/jcmm.13797

Wildhagen, K. C., Wiewel, M. A., Schultz, M. J., Horn, J., Schrijver, R., Reutelingsperger, C. P., et al. (2015). Extracellular histone H3 levels are inversely correlated with antithrombin levels and platelet counts and are associated with mortality in sepsis patients. Thromb. Res. 136, 542-547. doi: 10.1016/j.thromres.2015.06.035

Wu, Y., Ren, J., Zhou, B., Ding, C., Chen, J., Wang, G., et al. (2015). Gene silencing of non-obese diabetic receptor family (NLRP3) protects against the sepsisinduced hyper-bile acidaemia in a rat model. Clin. Exp. Immunol. 179, 277-293. doi: $10.1111 /$ cei.12457

Xie, Z., Guo, Z., and Liu, J. (2018). Whey acidic protein/four-disulfide core domain 21 regulate Sepsis pathogenesis in a mouse model and a macrophage cell line via the stat3/Toll-Like Receptor 4 (TLR4) signaling pathway. Med. Sci. Monit. 24, 4054-4063. doi: 10.12659/MSM.907176

Xu, J., Zhang, X., Pelayo, R., Monestier, M., Ammollo, C. T., Semeraro, F., et al. (2009). Extracellular histones are major mediators of death in sepsis. Nat. Med. 15, 1318-1321. doi: 10.1038/nm.2053

Conflict of Interest: The authors declare that the research was conducted in the absence of any commercial or financial relationships that could be construed as a potential conflict of interest.

Copyright (c) 2020 Shi, Wang, Chen, Jiao, Pei and Gong. This is an open-access article distributed under the terms of the Creative Commons Attribution License (CC $B Y)$. The use, distribution or reproduction in other forums is permitted, provided the original author(s) and the copyright owner(s) are credited and that the original publication in this journal is cited, in accordance with accepted academic practice. No use, distribution or reproduction is permitted which does not comply with these terms. 